\title{
Science in regulatory policy making: case studies in the development of workplace smoking restrictions
}

\author{
Lisa A Bero, Theresa Montini, Katherine Bryan-Jones, Christina Mangurian
}

Department of Clinical Pharmacy, Institute for Health Policy Studies, University of California, San Francisco, San Francisco, California USA

L A Bero

Department of Social and Behavioral

Sciences, Institute for Health Policy Studies, University of

California, San

Francisco

T Montini

Department of Clinical Pharmacy, University of California, San

Francisco

K Bryan-Jones

School of Medicine,

University of

California, San

Francisco

C Mangurian

Correspondence to:

Lisa A Bero, PhD, Professor,

Department of Clinical

Pharmacy and Institute for

Health Policy Studies,

University of California, San

Francisco, 3333 California

Street, Suite 265, San

Francisco, CA 94143-0936

(or 94118 for express mail

only), USA

bero@medicine.ucsf.edu

Received 5 April 2001 and in revised form 27 July 2001 Accepted 13 September 2001

\begin{abstract}
Objective-To study the role of science related and other arguments in the development of workplace smoking regulations. Design-Case study, content analysis

Subjects-Written commentaries and hearing transcripts on proposed indoor air regulations in Maryland and Washington.

Main outcome measures-We coded each written commentary and hearing testimony for position toward the regulation, affiliation of the person submitting it, criteria used to evaluate science and scientific, ideological, economic, political, engineering and procedural arguments.

Results-In both states, opposition to the regulations came primarily from the tobacco industry, small businesses, and business organisations and appeared to be coordinated. There was little coordination of public health support for the regulations. Arguments about science were used more often by those opposed to the regulations than by those in favour. Supporters emphasised the quantity of the evidence, while opponents criticised its reliability, validity, and quality. Arguments not related to science (61\% of total arguments; 459/751), were more common than scientific arguments (39\% of total arguments; 292/751). Economic and ideological arguments were used to a similar extent by regulation supporters and opponents.
\end{abstract}

Conclusions-Advocates can support health related regulations by submitting commentary emphasising the sound research base for regulation and countering criticisms of research. National coordination of these efforts could avoid duplication of effort and make more efficient use of limited public health resources.

(Tobacco Control 2001;10:329-336)

Keywords: workplace smoking regulations; science based arguments

Smoking restrictions are an important component of tobacco control policy because they protect non-smokers from the adverse health effects of passive smoking ${ }^{1-5}$ and facilitate smokers' decisions to quit or cut down. ${ }^{6}$ Furthermore, individuals living and working in smoke-free environments are less likely to begin smoking than those who are exposed to smoke. $^{7-10}$ The growing evidence on the adverse health effects of exposure to passive smoking has catalysed the development of workplace smoking restrictions. Of the 23 states in the USA that restrict smoking in private workplaces, two states (Maryland and Washington) do so through occupational safety and health regulations. ${ }^{11}$ The remaining states have legislative restrictions.

The different processes involved in regulatory policy development versus legislative policy development led us to expect that scientific evidence would play a prominent role in the development of regulatory policy. When elected legislators hold hearings on policy issues, their positions are often determined by commonsense judgments about what they believe is right, and the impact of the policy on their campaign contributors, political allies, and constituencies. ${ }^{12}$ Regulatory policy makers are somewhat of a hybrid of expert and politician. They are experts because they are technically proficient, or have professional staffs or scientific advisory committees who provide them with technical expertise. ${ }^{13}$ They are politicians in the sense that they are accountable to the governor, legislature, and organised interest groups. ${ }^{12}$

Legislators can hold hearings on a particular policy issue at which anyone can testify about proposed legislation, or they can decide on a policy issue without public input. In contrast, regulatory administrators must work as outlined in each state's Administrative Procedures Act. These acts require regulatory agencies to review the scientific basis for regulation, propose draft regulations, accept written public commentary and hold hearings on proposed regulations, consider all significant and relevant information, and then revise and finalise the regulation in light of the commentary received from interested parties. $^{13-15}$

Earlier studies of tobacco control policies have focused on the role of political factors including ideology and interest groups in influencing legislation, ${ }^{16-22}$ whereas this study examines regulations. Understanding regulatory as well as legislative policy development will be useful for advocates as they consider regulatory or legislative tobacco control strategies.

The goal of this study is to analyse the role of public input and the public's use of scientific argument and evidence in the development of workplace smoking regulations. We conducted a content analysis of the written commentaries and oral testimony submitted in the two states. Prior research on the development of 
regulatory policies has found that consideration of the scientific evidence is influenced by politics and social movements. ${ }^{23-27}$ Therefore, we analysed the use of scientific, political, ideological, and economic arguments used by opponents and supporters of the regulations. By studying the relative roles of research and other factors in policy formation, we can suggest strategies to optimise the evidence base for legislation. ${ }^{28}$ We determine whether (1) the criteria used to judge scientific evidence, (2) the arguments about the quality of the scientific evidence, and (3) the types of non-scientific arguments about the regulation vary by support for the regulation.

\section{Methods}

SELECTION OF CASES

We studied the development of workplace smoking regulations in Maryland and Washington because these are the only two states that have such regulation, and these regulations are more comprehensive than most existing state legislation. ${ }^{11}$

In late 1993, the Maryland Occupational Safety and Health Advisory Board (MOSH) proposed the Maryland Indoor Air regulation, banning smoking in almost all enclosed workplaces. The regulation was open to public comment from December 1993 to January 1994. Two hearings were held by the MOSH board in December 1993 and one by the Commissioner of Labor and Industry in May $1994 .^{29}$ The regulation was approved on 21 July 1994, but later modified by the state legislature to exempt workers in the hospitality industry (restaurants and bars). Even with the exemption of the hospitality industry workers, the Maryland regulation covered more types of workers than the Washington regulation, which restricted smoking only in offices.

In Washington, a series of incidents of "sick building syndrome" (respiratory and other illnesses associated with chemicals in indoor air) in government buildings, hospitals, and schools were reported to the Department of Labor and Industries during the early 1990s, and investigated by specialists from the University of Washington..$^{30-34}$ In August 1992, the Washington Department of Labor and Industries produced a draft regulation on indoor air quality in offices. In November and December 1993, public commentary was collected and six hearings were held. In 1993, the Department of Labor and Industries drafted a comprehensive indoor air regulation aimed at protecting workers from a variety of indoor air contaminants, including environmental tobacco smoke. Based on strong opposition from the public to the indoor air components of the proposed regulation, the director of the Department of Labor and Industries narrowed the regulation to focus only on tobacco smoke exposure. This narrower regulation was approved on 16 March 1994.

DATA SOURCES

All written commentaries and hearing transcripts were obtained from the MOSH Department of Licensing and Regulation and
Washington Department of Labor and Industries. We included substantive letters, reports, and the first copy of duplicate letters. We excluded non-substantive or illegible petitions, fact sheets, cover letters, postcards, electronic material (slides, videos), and handwritten submissions. In Maryland, 239 written commentaries and testimony from 119 individuals met the inclusion criteria. For Washington, we examined the 133 commentaries and 64 hearing testimonies that focused on passive smoking.

\section{DATA CODING}

We coded each written commentary and hearing testimony for position toward the regulation, affiliation of the person submitting it, and the arguments made. We developed coding categories inductively, based on initial data analysis, and in conjunction with categories used in previous, related research. ${ }^{35}$ Trained coders used a code book including decision rules. QSR-NUD*IST was used to facilitate data management and coding.

\section{Position toward regulation}

We coded each commentary or hearing testimony as being in favour of the regulation, against the regulation, or neutral (for example, pointing out typographical errors) toward the regulation. Neutral commentaries $(n=17)$ were excluded from further analysis.

\section{Affiliation}

We coded the affiliation of each person who submitted a written commentary or testified at a hearing into mutually exclusive categories (table 1). We coded individuals as tobacco industry affiliated if they (1) were an employee of a tobacco company (for example, Philip Morris) or an industry affiliated organisation (for example, Center for Indoor Air Research); (2) made their livelihood in tobacco production (for example, tobacco farmer); or (3) acknowledged that their commentary was prepared at the request of a tobacco company or tobacco organisation. Since we relied on self disclosures, we are likely to have underestimated the number of tobacco industry affiliated organisations or individuals. ${ }^{36}$

\section{Arguments}

The coders read each entire written commentary and hearing transcript and coded sections of text for the arguments made. A single text unit could be coded for multiple occurrences of an argument. We report the number of times that an argument occurred at least once in a written commentary or hearing testimony. The coding scheme had two components: (1) criteria used to evaluate science and scientific arguments; and (2) economic, ideological, political, and other arguments. For the purposes of this article, a "scientific" argument is defined as an argument that relied on research evidence, including, for example, basic science, epidemiology, engineering, or economic research. 
Table 1 Affiliations of people who submitted written commentary or testified on the Maryland and Washington Indoor Air Regulations by position toward the regulation

\begin{tabular}{|c|c|c|c|c|c|c|c|c|}
\hline \multirow[b]{3}{*}{ Affiliation } & \multicolumn{4}{|c|}{ Maryland } & \multicolumn{4}{|c|}{ Washington } \\
\hline & \multicolumn{2}{|c|}{$\begin{array}{l}\text { For } \\
(n=188)\end{array}$} & \multicolumn{2}{|c|}{$\begin{array}{l}\text { Against } \\
(n=157)\end{array}$} & \multicolumn{2}{|c|}{$\begin{array}{l}\text { For } \\
(n=141)\end{array}$} & \multicolumn{2}{|c|}{$\begin{array}{c}\text { Against } \\
(n=52)\end{array}$} \\
\hline & No. & $\%$ & $\overline{N o}$ & $\%$ & No. & $\%$ & $\overline{N o}$ & $\%$ \\
\hline Tobacco & 2 & 1 & 55 & 35 & 0 & 0 & 9 & 17 \\
\hline Other industry/corporation & 3 & 2 & 2 & 1 & 3 & 2 & 3 & 6 \\
\hline Small business owners & 23 & 12 & 17 & 11 & 16 & 11 & 18 & 35 \\
\hline Business/merchant organisation $\mathrm{s}$ & 3 & 2 & 24 & 15 & 2 & 1 & 3 & 6 \\
\hline Labour organisation & 2 & 1 & 14 & 9 & 0 & 0 & 1 & 2 \\
\hline Private practice/consulting & 9 & 5 & 4 & 3 & 0 & 0 & 4 & 8 \\
\hline Government & 28 & 15 & 6 & 4 & 17 & 12 & 2 & 4 \\
\hline Lay activist organisation & 53 & 28 & 1 & 1 & 32 & 23 & 0 & 0 \\
\hline Health professional organisation/provider & 10 & 5 & 0 & 0 & 34 & 24 & 0 & 0 \\
\hline University/college & 15 & 8 & 0 & 0 & 4 & 3 & 0 & 0 \\
\hline No affiliation & 37 & 20 & 34 & 22 & 32 & 23 & 12 & 23 \\
\hline \multirow[t]{2}{*}{ Unknown affiliation/other } & 3 & 2 & 0 & 0 & 1 & 1 & 0 & 0 \\
\hline & \multicolumn{4}{|c|}{$\mathrm{p}=0.0001$ Pearson $\chi^{2}$} & \multicolumn{4}{|c|}{$p=0.0001$ Pearson $\chi^{2}$} \\
\hline
\end{tabular}

The $\chi^{2}$ statistic was used to test for differences in the distribution of affiliations between commentators in support of the regulation and commentators against. The distribution of affiliations was significantly different between the two groups in both Maryland and Washington.

Table 2 Science evaluation criteria used by those who submitted written commentary or testified on the Maryland and Washington Indoor Air Regulations by position toward the regulation

\begin{tabular}{|c|c|c|c|c|c|c|c|c|}
\hline \multirow{3}{*}{$\begin{array}{l}\text { Criteria for } \\
\text { evaluation science }\end{array}$} & \multicolumn{4}{|c|}{ Maryland } & \multicolumn{4}{|c|}{ Washington } \\
\hline & \multicolumn{2}{|c|}{ For $(n=188)$} & \multicolumn{2}{|c|}{ Against ( $n=157)$} & \multicolumn{2}{|c|}{ For $(n=141)$} & \multicolumn{2}{|c|}{ Against $(n=52)$} \\
\hline & No. & $\%$ & No. & $\%$ & No. & $\%$ & No. & $\%$ \\
\hline Quantity & 46 & 25 & 20 & 13 & 62 & 44 & 16 & 31 \\
\hline Reliability & 20 & 11 & 25 & 16 & 18 & 13 & 11 & 21 \\
\hline Quality & 14 & 7 & 25 & 16 & 3 & 2 & 3 & 6 \\
\hline \multirow[t]{2}{*}{ Validity } & 4 & 2 & 8 & 5 & 0 & 0 & 3 & 6 \\
\hline & \multicolumn{4}{|c|}{$\mathrm{p}=0.251$, Fisher's exact } & \multicolumn{4}{|c|}{$p=0.004$, Fisher's exact } \\
\hline
\end{tabular}

Fisher's exact test was used to test for differences in the distribution of the proportions of types of scientific arguments used between commentary in support of the regulation and commentary against. The distribution of arguments was significantly different between the two groups in against. The
Washington.

Analysis

We did a content analysis to compile descriptive statistics that allowed us to detect patterns of position on regulation, affiliation or type of argument made. ${ }^{37}$ We analysed the states separately because we expected variation that could be attributed to scope of the regulation (all workplaces $v$ offices), distinct historical genesis of the regulation (accident $v$ "sick buildings"), and to geography (Eastern tobacco producing state $v$ Pacific Northwest state) ${ }^{23}$ We compared the extent and types of arguments and counter arguments used by supporters and opponents of regulation. The $\chi^{2}$ statistic or Fisher's exact test, as appropriate, was used to test for differences in affiliations and proportions of arguments used between commentary in support of the regulation and commentary against.

\section{Results}

POSITION TOWARD REGULATION AND AFFILIATIONS

As shown in table 1, those in favour of the regulation submitted more written commentary or testified at hearings more than those who were opposed to regulation. The distribution of affiliations differed between supporters and opponents of regulation. Those in support of the regulation were more likely than those against to represent lay activist associations (such as Action on Smoking or Health), health professionals, or government employees (table 1).
Overall, about one quarter of the opposition to the regulation came directly from the tobacco industry. There was some duplication between the tobacco industry affiliated commentaries in Washington and Maryland. For example, Philip Morris submitted over 40 binders (15 429 pages) of duplicate material to Maryland and Washington. With just one exception, ${ }^{\dagger}$ the tobacco industry unanimously opposed the regulations. The remainder of the opposition was primarily from small business owners, business organisations, and labour organisations.

OVERVIEW OF ARGUMENTS

Overall, more arguments were made in support of regulation $(\mathrm{n}=454)$ than in opposition ( $\mathrm{n}=297)$. Arguments not related to science, particularly economic, ideological, political, and procedural arguments ( $61 \%$ of total arguments; 459/751), were more likely to appear in commentary and hearings than scientific arguments (39\% of total arguments; 292/751).

\section{SCIENTIFIC ARGUMENTS}

Criteria for evaluating science

Overall, 45\% (87/193) of the Washington commentary and $27 \%(93 / 345)$ of the Maryland commentary referred to criteria for evaluating science. As shown in table 2, supporters of regulation were more likely to mention the quantity of evidence available about the adverse health effects of passive smoking. For example, supporters of regulation pointed out that scientific consensus had already been reached about the health effects of passive smoking:

"ETS has been declared a human carcinogen by all the major scientific and medical organizations, both nationally and internationally and it is estimated to cause 3000 cancer deaths each year (Maryland commentary)."

In contrast, opponents of regulation attacked the reliability, validity, and quality of the evidence base (table 2). Criticisms about the reliability of the evidence often claimed that the data on the health effects of passive smoking remained controversial:

"Other researchers who have reviewed the reported findings concerning the possible relationship between PTS [passive tobacco smoke] and respiratory symptoms and diseases in adults also contend that the results are mixed and inconclusive. (Maryland commentary)"

When opponents criticised the validity of the scientific evidence, they often assailed the measurement of passive smoke exposure:

"All of the epidemiologic studies on the purported associations between living with a

† One person who submitted both a written commentary and gave oral testimony in favour of the Maryland regulation was tobacco industry affiliated. This commentary was submitted by Robert Glenn of the Maryland Industrial Hygiene Council and was coded as tobacco industry affiliated because the commentary stated that it was submitted at the request of Bruce Bereano, an attorney for the Tobacco Institute. Although the Tobacco Institute requested the commentary, it concluded:

"Smoking in the workplace represents a major source of exposure to toxicants for which the employer has a duty and obligation to protect his or her employees ... There should be renewed efforts by regulatory agencies and companies to eliminate smoking in the workplace. I would ask that you support Maryland occupational safety and health regulations to prohibit smoking in the workplace." 


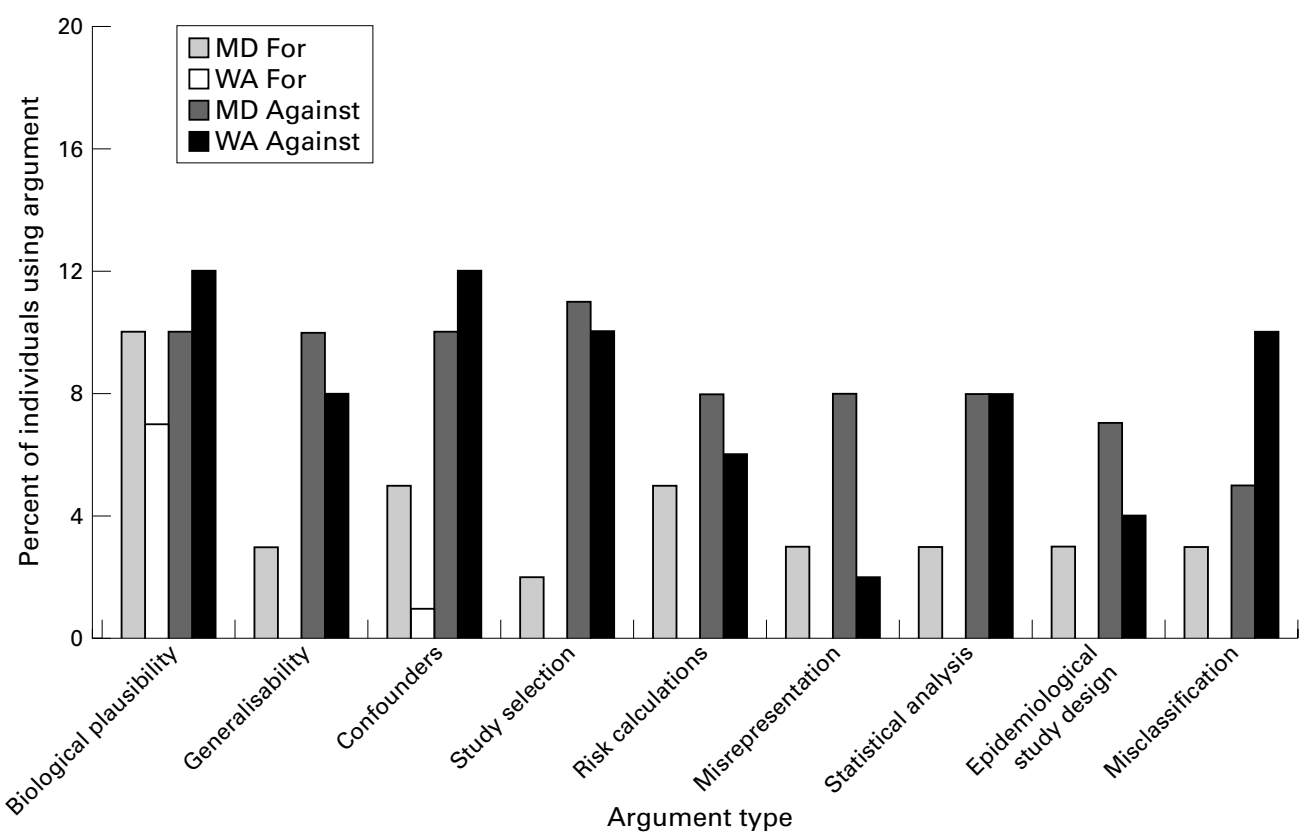

Figure 1 Scientific arguments. MD, Maryland; WA, Washington.

smoker and disease in non-smokers rely solely upon questionnaire responses about reported exposure, rather than upon actual ETS exposure data. Recent studies indicate that questionnaires are an extremely unreliable and inaccurate measure of exposure. (Washington commentary)"

Peer review was often mentioned as a criterion for assessing quality, as shown by this testimony from a scientist in favour of regulation:

"The entire body of data that I showed you is published in the peer reviewed scientific literature . . .It doesn't do anybody any good to publish this stuff in non-peer reviewed journals. If it's going to be useful, it has to go through the rigors of peer review, and, as all scientists discover, it is a very good process because often you do make errors when you do science, and it's nice to have one or two or three - and I've had as many as six on some of my more controversial papers - six reviewers, and it's a big help. (Maryland hearing)"

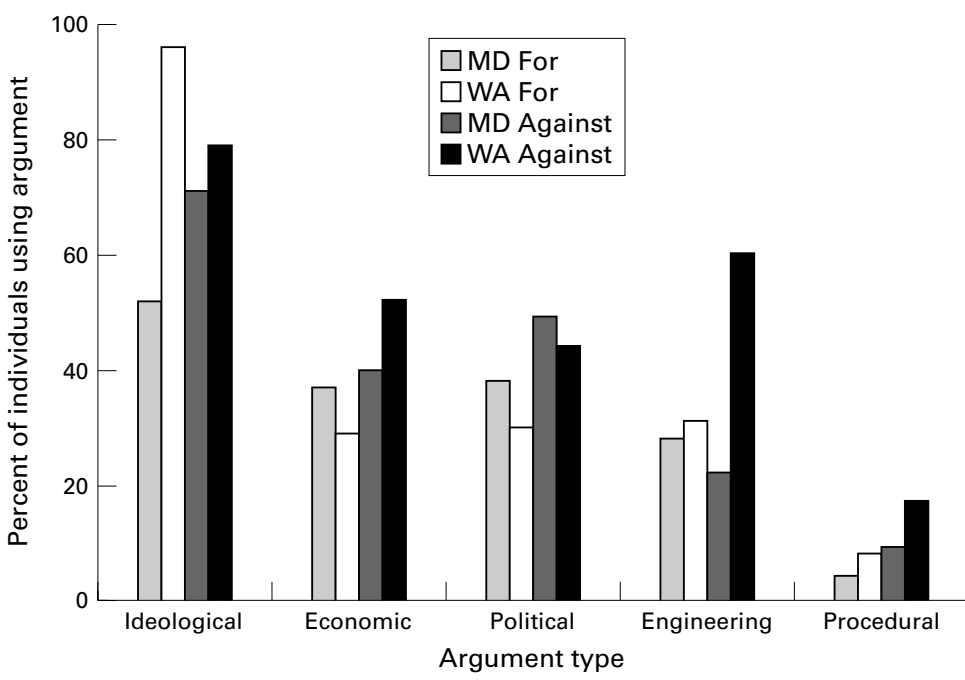

Figure 2 Non-science arguments.
At another hearing, the regulators questioned an engineer who was testifying on behalf of the Tobacco Institute:

"Regulator: Just to make sure I'm clear, are the two papers you referred to on the absence of nicotine and research related to tobacco smoke, are they part of the record?

Engineer: No, but I can certainly make them part of the record.

Regulator: Have they been through peer review?

Engineer: Oh, yes.

Regulator: I would like any documentation on what peer review they went through.

Engineer: Yes, they both appeared in peer reviewed journals. Well, actually, they were both peer reviewed conference proceedings. (Maryland hearing)"

As this testifier suggests, the rigour of peer review can vary between journals and conference proceedings. ${ }^{36}$

\section{Specific arguments about science}

Most of the commentaries and testimony that discussed the quality of the evidence also gave detailed critiques of the research methods. Figure 1 shows that opponents of regulation were more likely to use scientific arguments than supporters. This difference was significant in Washington $\left(\mathrm{p}=0.0002, \chi^{2}\right)$, but not Maryland $\left(\mathrm{p}=0.8197, \chi^{2}\right)$.

A common strategy of opponents of regulation was to focus on a single aspect of a study, rather than the study as a whole. Opponents of regulation often criticised the methods of studies on the health effects of passive smoking based on their generalisability, inability to control for confounding factors, selection of studies included in literature reviews, and misclassification bias (fig 1). Although there are strong methodological rebuttals of each of the scientific arguments against the regulations, ${ }^{38}$ commentaries in favour of the regulation rarely contained arguments about the science (fig 1). In Washington, for example, 
those in favour of regulation used only the arguments about confounding and biological plausibility.

\section{Non-science arguments}

As shown in fig 2, political, engineering, and procedural arguments were used more frequently by regulation opponents than supporters. Ideological and economic arguments were used to a similar extent by both supporters and opponents.

Ideological arguments centred around protecting non-smokers, maintaining the rights of smokers, government intrusion, and the appropriateness of smoking restrictions as policy solutions. Many opponents of regulation expressed their concern that smokers' rights were being violated, and that workers should have a choice to smoke on the job. A delegate to the Maryland assembly, who testified at the bequest of the Tobacco Institute, reflected this view:

"I'm not here saying everybody should be smokers. But I am saying that there is such a thing as a freedom of choice and that those who do smoke have some rights, and I don't think all their rights should be taken away from them ... I've been in the House of Delegates for 16 years, and I think I'm almost at the point where I believe that if you pass a law you ought to take one off. We've regulated people, the next thing we're going to tell them how many times they're going to have to chew their steak so they won't swallow wrong. (Maryland hearing)"

Supporters of regulation noted that non-smokers had rights as well, as did this federal government employee who testified after the delegate:

"This is not to deny "smokers' rights", it is to give non-smokers equal opportunities for a clean area. Why should a smoker have the choice to foul "clean air" while the non-smoker nearby may have no choice but to breathe smoke contaminated air. (Washington commentary)"

Opponents consistently reiterated their belief that protecting workers from exposure to tobacco smoke was unwarranted government intrusion. This president of a chain of tobacconists expressed his concern regarding the slippery slope of government protection:

"Where does the intrusion into personal rights by the government stop? Our economy has been built on the ingenuity and creativity of individuals to develop business. With excessive controls we stagnate and "Big Brother" takes over. Let business operate as business does best. If employees, or customers, want to work in the environment that management has created, they will do so. If they don't they will go elsewhere, but let management determine how business is to be run. (Maryland hearing)"

Later in that same hearing, a representative of the American Heart Association responded:

"[I]f we were to leave it up to those people who cry "government regulations," there would not be sneeze guards over salad bars and restaurant employees would not be required to wash their hands before handing food. (Maryland hearing)" Economic arguments, like ideological arguments, were frequently used by both supporters and opponents of regulation (fig 2). Supporters of regulation argued that the regulation would decrease smoking related diseases and, therefore, the cost to the state of caring for people with these diseases:

"If the state does not move to provide a smoke-free environment in the workplace, more and more workers are going to seek compensation for smoke related illnesses. (Maryland hearing)"

Opponents of the regulation argued that enforcing the regulation would cost the state money:

"However, what will be the cost to hire more L \& I workers to make checks of air quality, to seek and find those not in compliance and to issue citations, etc? What will it cost Washington tax payer to have all state buildings brought into some type of compliance? (Washington commentary)"

One opponent contended that the regulation would hurt his business and, ultimately, the entire state:

"I can't market my business and make it grow as much as I should be able to, thereby costing this state jobs that I would love to create. (Washington commentary)"

In contrast, regulation supporters argued that the regulation was actually good for business:

"It [voluntary restaurant smoking ban] has helped manage the restaurant, it's assisted us in seating our guests and inevitably there's a smile on guests' face when they ask for a non-smoking section and we tell them that our entire restaurant is non-smoking. It's received with almost entire pleasure. (Maryland hearing)"

Procedural and political arguments were used more often by opponents of regulation than supporters (fig 2). A consistent theme among these arguments was challenging the legitimacy and the authority of the administrative board to regulate exposure to tobacco smoke in the workplace. Other opponents asserted that restricting smoking in the workplace should be legislated not regulated. Still others asked the board to wait for the federal Occupational Safety and Health Administration (OSHA) to promulgate its indoor air regulation before acting.

In Washington, procedural arguments included discussions of the scope of the regulation. The Washington regulation was originally proposed as a comprehensive indoor air regulation. Thus, there was much discussion regarding the broadness of the regulation to cover all indoor air toxins. Supporters of smoking restrictions argued that the regulation should be narrowed to cover only passive smoking because they feared that regulating indoor air quality was complicated and that the process would take too long. ${ }^{39}$

Arguments about building engineering and ventilation were used more frequently by opponents of regulation (fig 2). They offered ventilation as a solution, contending that health protections could be achieved with adequate ventilation or banning smoking. Supporters of the regulation countered that separate ventilation systems for smoking rooms would be technologically difficult and prohibitively expensive. One physicist testified at the Maryland hearing:

"Let's look at the probability of lung cancer death in a workplace as a function of ventilation rate. Now, the tobacco industry - in the form of $\mathrm{Mr}$ 
Turner-has suggested that ventilation is a very good control measure for environmental tobacco smoke. Here's ASHRAE's 62-1989, which is the ventilation standard currently promulgated by the American Society of Heating, Refrigerating and Air Conditioning Engineers: 20 cubic feet per minute per occupant. That corresponds to a risk which is of the order of $10^{-3}$. If we wanted to get it down to a $10^{-6}$ level, which is the bottom line here, you can see we would have to have ... 10000 cubic feet per minute per occupant, or better, to get it down that way. (Maryland hearing)"

This witness is testifying that, in effect, a tornado would need to be created in the room in order to reduce passive smoke to a level that is not harmful.

\section{Discussion}

Support for the workplace smoking regulations came primarily from lay activist organisations, health care providers or professional organisations, and government workers, and appeared to be uncoordinated within or between states. Opposition to the regulations came primarily from tobacco industry affiliated individuals, small businesses, and business organisations. Similarities in the material submitted by opponents of the regulation in Maryland and Washington suggest that the opposition was organised at a national level. Internal industry documents suggest that the opposition from small business owners and merchant organisations could have resulted from industry efforts. $^{40}$

Although the regulatory process requires that scientific evidence be considered when developing a regulation, ${ }^{14}$ economic, political, and ideological arguments were more likely to appear in commentary and hearings than scientific arguments. This finding confirms trends observed in the analysis of legislative tobacco control policy. ${ }^{18}$ Economic and ideological arguments were used to a similar extent by regulation supporters and opponents.

Although scientific arguments were used less frequently than other types, arguments about the science were used more often by those opposed to the regulations than by those in favour. In both states, those opposed to the regulations attempted to reduce regulators' confidence in the research evidence upon which the regulations were based. The criteria used to evaluate the evidence base for the regulation differed between those opposing or favouring the regulation. Supporters emphasised the quantity of the scientific evidence, while opponents criticised its reliability, quality, and validity. Numerous scientific studies regarding the health effects of passive smoking and the economic impact of smoking restrictions exist. However, those in favour of the regulation often failed to mention these studies in order to counter the criticisms of the science. Those favouring regulation may have believed that the scientific evidence supporting the workplace health restriction was well accepted and that there was no need to restate the evidence.
Tobacco industry emphasis on the science is most likely due to two factors: one historical, the other strategic. The tobacco industry, like other corporations that are subject to regulation, has used a number of tactics to prevent regulation of their product. ${ }^{41-43}$ For years, the industry has funded and published research that supports alternative explanations for the adverse health effects associated with passive smoking, as well as criticised research that finds an association of passive smoking and adverse health effects. ${ }^{3644}$ We have shown previously that original research articles from symposia proceedings, such as those cited in the public commentary by the tobacco industry, use different standards for peer review and are of poorer methodological quality than articles from peer reviewed journals. ${ }^{48-50}$ Our findings suggest that the industry has used some of their funded critiques to undermine the science that underlies regulation of passive smoke and infuse the development of tobacco control regulations with controversy. ${ }^{51}$ When these two regulatory efforts were launched almost simultaneously in the two states, the tobacco industry was able to produce volumes of written commentary critiquing the science that underlies workplace smoking restrictions and send their paid scientific advisors to hearings.

The second factor possibly underlying the tobacco industry's constant critique of the science is strategic. The few times that public health advocates invoked the science, they explained that the cumulative body of research fortified the imperative of smoking bans. Tobacco industry spokespersons did not like the conclusions of this body of literature, so they attacked the methods by which they were reached, fragmenting the science into acontextualised slices of single studies which they criticised. Strategically this serves multiple purposes. Firstly, it is an attempt to construct scientific uncertainty. Policy makers depend upon public and politicians' support of their work, and if a policy seems controversial or unfounded, or if the preparatory review work of regulators appears to be lacking, there may be pressure to postpone action. The fact that the tobacco industry is presenting lengthy and complex highly technical and narrowly specified critiques of mere slices of the whole body of science evidence may be lost on audiences of public proceedings. Secondly, as noted by Murphy, ${ }^{52}$ this narrow focus on research methodology is an attempt to redefine the parameters of the issue, and allows the tobacco industry to withdraw from considerations of other issues, such as its social responsibility. Opponents of other health regulations have also relied on scientific claims to argue for the responsible use of science and to redefine public health issues. ${ }^{53}$

Public input into the regulatory process offers opportunities for public health activists to correct all factually misleading claims of the tobacco industry, and continue to frame the issues inherent in tobacco control policy. ${ }^{21} 3954$ Public health advocates should also organise credible, legitimate scientists to testify at public 
hearings in order to explain the strength of the scientific evidence and defuse criticisms of omission, errors, biases, and poor procedures inherent in the evidence base. ${ }^{55}$ This implies a great deal of coordination on the part of tobacco control activists, and is possible through the use of the internet. Coordination of public health activists' efforts is also pivotal in anticipating the political, economic, and ideological arguments and planning counterarguments. As presented above, many tobacco control activists formulated cogent political, economic, and ideological arguments that could be deployed across policy making sites. For example, at these public hearings the tobacco industry representatives contended that smoking bans infringe upon smokers' freedom of choice, and violate the rights of smokers. Public health advocates countered by distinguishing between voluntary and involuntary exposure, explaining that workplace exposure is involuntary exposure. Those who earn their living in an indoor workplace do not have a choice as to whether or not to be exposed to passive smoking while they are at work. They further countered the "smoker's rights" issue by contending that non-smokers have rights as well. ${ }^{56}$ They also pointed out that smoking denies people with asthma, chronic bronchitis, and emphysema access to public places. In some nations the rights of people with disabilities to equal access to all places, and reasonable accommodation within all public spaces, is guaranteed by law. ${ }^{57}$ These points and counter points could be finely honed and shared by various public health groups all over the world. ${ }^{21}$

Our findings suggest strategies for supporting health related regulations. Firstly, supporters of regulations could keep the issue framed as a scientific one by submitting commentary that emphasises the sound research base for the regulation. Secondly, supporters of regulation could counter the criticisms of the research on which the evidence is based. Lastly, organisation of these efforts to support regulation at a national level, rather than a local level, could avoid duplication of effort and make more efficient use of limited public health resources.

We thank Marieka Schotland, Theo Tsoukalis, Ruth Malone, and Elizabeth Boyd for useful comments on the manuscript, and Peter Bachetti for statistical advice. This work was supported by grants from the American Cancer Society (RPG9714301PBP) and the University of California TobaccoRelated Disease Research Program (6RT0025).

1 Steenland K. Passive smoking and risk of heart disease. fAMA 1992;267:94-9.

2 Glantz SA, Parmley WW. Passive smoking and heart disease: epidemiology, physiology and biochemistry. Circudation $1991 ; 83: 1-12$.
latease

3 United States Environmental Protection Agency. Respiratory health effects of passive smoking: lung cancer and other disorders. Washington, DC: Indoor Air Division, Office of Atmospheric and Indoor Air Programs, Office of Air and Radiation, United States Environmental Protection Agency, 1992.

4 US Department of Health and Human Services. The health consequences of involuntary smoking. A report of the Surgeon Genters 1986. Rockville, Maryland. Pub (DHHS Publication Nenters for Disease

5 National Research Council. Environmental tobacco smoke: measuring exposures and assessing health effects. Washington DC: National Academy Press, 1986.

\section{What this paper adds}

Smoking restrictions can be promulgated through legislation or regulation. Earlier studies have focused on the role of political factors including ideology and interest groups in influencing legislation. In this study, we focus on the development of smoking restriction regulations and analyse the role of public input and the public's use of evidence in regulation development. Arguments about science and how science should be evaluated play a role in regulation development. Economic and ideological arguments also appear frequently in discussions of regulation. Advocates can support health related regulations by submitting commentary emphasising the sound research base for regulation and countering criticisms of research.

6 Chapman S, Borland R, Brownson R, et al. The impact of workplace smoking bans on declining cigarette consumpwork in Australia and the USA. Am f Public Health 1999;89:1018-23.

7 Patten CA, Gilpin E, Cavin SW, et al. Workplace smoking policy and changes in smking behaviour in California: a suggested association. Tobacco Control 1995;4:36-41.

8 Pierce J, Gilpin E, Emery S, et al. Has the California tobacco control program reduced smoking. FAMA 1998;280:893-

9 Wakefield MA, Chaloupka FJ, Kaufman NJ, et al. Effect of restrictions on smoking at home, at school, and in public places on teenage smoking. cross sectional study [see comments]. BMF 2000;321:333-7.

10 Farkas AJ, Gilpin EA, White MM, et al. Association between household and workplace smoking restrictions and adolescent smoking. $¥ A M A$ 2000;284:717-22.

11 Welch C, ed. State legislated actions on tobacco issues. Washington DC: American Lung Association, 1998.

12 Peterson MA. The limits of social learning: translating analysis into action. F Health Politics, Policy and Law 1997; 22:1077-114

13 Faigman DL. Legal alchemy: the use and misuse of science in the law. New York: WH Freeman and Company, 1999

14 Stone A. Regulation. In: Shafritz JM, ed. International encyclopedia of public policy and administration. Boulder: Westview Press, 1998:1943-8.

15 Buffler PA, Kyle AD. Regulatory reform proposals and public health [editorial]. Environ Health Perspect 1996; 104:356-61.

16 Monardi F, Glantz SA. Are tobacco industry campaign contributions influencing state legislative behavior? Am $\mathcal{F}$ Public Health 1998;88:918-23.

17 Jacobson PD, Wasserman J, Raube K. The politics of anti-smoking legislation: lessons from six states. $\mathcal{F}$ Health Politics Policy Law 1993;18:787-819.

18 Jacobson PD, Wasserman J, Anderson JR. Historical overview of tobacco legislation and regulation. Fournal of Social Issues 1997;53:75-95.

19 Glantz S, Begay M. Tobacco industry campaign contributions are affecting tobacco control policy making in tions are affecting tobacco control

20 Cohen J, Goldstein A, Flynn B, et al. State legislators' perceptions of lobbyists and lobbying on tobacco control issues. Tobacco Control 1997;6:332-6.

21 Cohen J, Milio M, Rozier R, et al. Political ideology and tobacco control. Tobacco Control 2000;9:263-7.

22 Goldstein A, Cohen J, Flynn B. State legislators' attitudes and voting intentions about tobacco control legislation. Am F Public Health 1997;87:1197-200.

23 Nathanson CA. Social movements as catalysts for policy change: the case of smoking and guns. $f$ Health Politics Policy and Law 1999;24:421-88.

24 Jasanoff S. EPA's regulation of daminozide: unscrambling the messages of risk. Science, Technology, \& Human Values 1987;12(3 \& 4):116-24

25 Hanson JD, Logue KD. The costs of cigarettes: the economic case for ex post incentive-based regulation. Yale Law fournal 1998;107:1163-262.

26 Jacobson PD, Warner KE. Litigation and public health policy making: the case of tobacco control. f Health Politics Policy and Law 1999;24:769-804.

27 Wilson JQ. Bureaucracy: what government agencies do and why they do it. Baltimore, Maryland: Johns Hopkins University Press, 1989.

28 Gray JAM. Evidence-base healthcare: how to make health policy and management decisions. New York: Churchill Livingand manageme

29 Maryland Occupational Safety and Health Administration, Department of Licensing and Regulation. Decision of 
Commissioner of Labor and Industry on proposed regulation to prohibit smoking in enclosed workplaces. Maryland Register 1994;21:1336-52.

30 Lange L. What makes buildings sick: chemicals in stale air blamed for many workplace maladies. Seattle PostIntelligencer 5 March 1990;A1.

31 Bock P. District can't cure pollution problem in 'sick' school. The Seattle Times 7 February 1991;C3.

32 Bock P. City likely stuck with bill for sick school-Pupils breathe easier after revisions at Hay Elementary. The Seattle Times 17 April 1992;B1.

33 Taylor R. Operators blame Harborview for illnesses; Improvements made to 'sick building,' but complaints continue. Seattle Post-Intelligencer 26 December 1991;B1.

34 Williams H. 'Sick Buildings' vex office workers but elude regulation. The Seattle Times 26 September 1990;H1.

35 Bero LA, Glantz SG. Tobacco industry response to a risk assessment of environmental tobacco smoke. Tobacco Control 1993;2:103-13.

36 Bero L, Galbraith A, Rennie D. Sponsored symposia on environmental tobacco smoke. $\mathscr{f} A M A$ 1994;271:612-17.

37 Morgan DL. Qualitative content analysis: a guide to path not taken. Qualitative Health Research 1993;3:112-21.

38 Repace JL, Lowrey AH. Issues and answers concerning passive smoking in the workplace: rebutting tobacco industry arguments. Tobacco Control 1992;1:208-19.

39 Montini T, Bero LA. Policy makers' perspectives on public health advocates' roles in regulation development. Tobacco Control 2001;10:218-24.

40 Mangurian C, Bero L. Lessons learned from the tobacco industry's efforts to prevent the passage of a workplace smoking regulation. Am f Public Health 2000;90:1926-30.

41 Lilienfeld D. The silence: the asbestos industry and early occupational cancer research-a case study. Am f Public Health 1991;81:791-800.

42 Rosner D, Markowitz G. A 'Gift of God'?: the public health controversy over leaded gasoline during the 1920s. Am F Public Health 1985;75:344-52.

43 Tsoukalas T. Lead poisoning research and public health policy in the United States (1924-1987): an analysis of
institutional failure. Research in Social Problems and Public Policy 1999;7:83-103.
44 Barnes D, Hanauer P, Slade J, et al. Environmental tobacco smoke: the Brown and Williamson documents. $7 A M A$ smoke: the Brown

45 Barnes D, Bero L. Industry-funded research and conflict of interest: an analysis of research sponsored by the tobacco industry through the Center for Indoor Air Research. $f$ Health Politics, Policy and Law 1996;21:515-42.

46 Bero L, Barnes D, Hanauer P, et al. Lawyer control of the tobacco industry's external research program: The Brown and Williamson documents. FAMA 1995;274:241-7.

47 Hanauer P, Slade J, Barnes DE, et al. Lawyer control of internal scientific research to protect against products liability lawsuits: the Brown and Williamson documents. fAMA 1995;274:234-40.

48 Barnes D, Bero L. Scientific quality of original research articles on environmental tobacco smoke. Tobacco Control 1997;6:19-26.

49 Bero LA, Galbraith A, Rennie D. The publication of sponsored symposiums in medical journals. New Engl f Med 1992;327:1135-40.

50 Cho M, Bero L. The quality of drug articles published in symposium proceedings. Ann Intern Med 1996;124:485-9.

51 Kennedy GE, Bero LA. Print media coverage of research on passive smo

Affiliation bias and expert disagreement in fram ing the nicotine addiction debate. Science, Technology, $\mathcal{E}$ Human Values 2001;26:278-99.

53 Drieger SM, Eyles J. Organochlorines and breast cancer: the use of scientific evidence in claimsmaking. Soc Sci Med 2001;52:1589-605.

54 Pross A, Stewart I. Breaking the habit: attentive publics and tobacco regulation. In: Phillips S, ed. How Ottawa spends 1994-95: making change. Ottawa: Carleton University Press, 1994.

55 Hilgartner S. Science on stage : expert advice as public drama. Stanford, California: Stanford University Press, 2000.

56 Americans for Nonsmokers'Rights. URL: http://www.nosmoke.org/, 2001.

57 Action on Smoking and Health (ASH) URL: http://ash.org/. 2001. 